\title{
The "MelArete" Project: Educating children to the Ethics of Virtue and of Care
}

\author{
Luigina Mortari \\ University of Verona, ITALY
}

\author{
Marco Ubbiali * \\ University of Verona, ITALY
}

Received: April 27, 2017 - Revised: July 4, 2017 - Accepted: July 10, 2017

\begin{abstract}
The educative project MelArete proposes an interpretation of ethical education: a form of Education to Virtue Ethics in the light of the philosophy of care. Starting from the ontological assumption that care is prime in life and without it the human being cannot flourish in his/her humanity, the project is based on an interpretation of the pedagogy of care. Since the practice of care reveals to have an ethical core and that core is made of ways of being-with-the-others, the pedagogical theory of MelArete states that in order to develop a project that is in relationship with the core of life we must educate to care. Therefore, educating to care means educating to virtues. On this basis MelArete proposes activities with the aim to guide children's attention to the concepts of care and virtues. MelArete has its many references in Plato and Aristotle; besides it assumes the distinction of Ricoeur between ethics and morality. In Plato/Socrates (Alcibiades I) ethics is an educational action that allows the others to thrive in their own existential capabilities; moreover, in Aristotle's (Nicomachean Ethics) ethics searches for eudaimonia, a good quality of life. In our educational project with children, the educative methods are the following: conversations (promoting intersubjective thought), narratives (reading and writing stories about virtues), vignettes and games (stimulating ethical thinking through a playful language) and the "diary of virtues" (promoting a reflecting culture of virtues in everyday life). In this paper we present the theoretical background of the project and a summary of the pedagogical approach and application which we are testing in our research.
\end{abstract}

Keywords: Ethical education, ethics of virtue, ethics of care, kindergarten, primary school.

To cite this article: Mortari, L., \& Ubbiali, M. (2017). The "MelArete" Project: Educating children to the ethics of virtue and of care. European Journal of Educational Research, 6(3), 269-278. doi: 10.12973/eu-jer.6.3.269

\section{Introduction}

\section{The Relevance of Ethical Education}

The necessity of ethics

In human experience there are essential and unavoidable things, even if it very often occurs that what is ontically proximal (i.e. evident in everyday life) can be unknown in its ontological meaning (Heidegger, 1996). A primary evidence is given by the phenomenon of care: care is essential because human life cannot flourish without it. Everybody feels the necessity to feel good and defend him/herself from pain: care is the required answer to this necessity (Noddings, 2002).

Ancient wisdom has theorized the ontological need for care. In Phaedrus Plato affirms that care is not only a human characteristic but it is also a trait of gods: Zeus is described as a god who acts "ordering all and taking care of all" (246e).

In the Republic Socrates explains to Glaucon that since philosophers can rule the polis (because of their knowledge of what is beautiful, just and good), they should "have a care and providence of others" (520a).

According to Plato/Socrates care is an action that benefits the person who is the object of the action of care (Plato, Euthyphro, 13b), with the aim of the full flowering of his existential capacities (Plato, Alcibiades I, 129a).

\footnotetext{
* Corresponding author:

Marco Ubbiali, University of Verona, Department of Human Sciences, Italy.

Email:marco.ubbiali@univr.it
} 
In the 20th century Martin Heidegger renewed the interest in care and developed an original reflection: care is an essential ontological trait of the Dasein, its being structure, so that everybody is what he/she does and what he/she cares about (Heidegger, 1996).

Emmanuel Lévinas states that as soon as he/she comes to light every human being has the need to take care of his/her life in order to get a solid form and to be conserved in the being (Lévinas, 2000).

To a deep analysis it appears that an essential trait of the human ontological substance is that of vulnerability and fragility (Mortari, 2015). Human being is fragile because he/she is not self-subsistent; he/she is in need of being and has to look for it. Human being is vulnerable because he/she is always exposed to external forces that can wound him/her. The good that is present in the being can easily fail; it can degrade. It takes very little to create a situation of discomfort, a condition of painful intolerance. The violence of gestures or words is not necessary; instead, the carelessness and indifference of the non-Samaritan suffice to turn to the other side. Our awareness of the other's vulnerability demonstrates the necessity of responsibility for one another-the generative root of the ethical act (Pulcini, 2009).

If we accept the idea that human condition is characterized by plurality (Arendt, 1958), as a plural-singularity (Nancy, 2000) and as an original sociality (Lévinas, 2000) we can affirm that being is being-with: it is not sufficient in and of itself. We need others as much as others need us. The answer to the other's "neediness" is care. The fact that everyone needs care makes self-evident that we must take care of the others. It is the continuous exchange of care that makes life possible. Coexisting implies to take care of the others. In this sense, taking care of the others is not just a possible ontological perspective, but a necessity for the whole existence.

But what is care? Care is a practice through which a person takes to heart the other in order that she/he can have what is necessary to conserve and protect her/his life, to make the existential possibilities of life flourish and to mend the wounds of soul and body.

To make it possible to educate to care it results necessary to identify what are the essential qualities of a caring behaviour. At this aim, the practice of care has been investigated both trough a literature review in the philosophy of the past (ancient: Plato, Seneca; recent: Heidegger, Lévinas) and of the present (Noddings, Held, Bowden, Tronto) (the results are in Mortari, 2006; 2015), and through an empirical investigation that assumed as object the experience of caring people (mothers, teachers, nurses). From this double investigation it emerged that care, since it is a practice, reveals itself through ways of being: to pay attention, to listen to, to be present, to act with delicacy, to pronounce words that attest a thoughtful consideration for the other, to show empathy, etc. But at the core of these ways of being it emerged to be intimate ethical postures as to have respect, to be generous, to have courage, to feel oneself responsible for the other: since these postures can be identified as virtues, it is legitimate to state that the intimate core of care is an ethics of virtues. From this assumption it emerges that educating to care means educating to virtues.

\section{Towards a Definition of Ethics}

\section{What is Ethics?}

Philosophical reflections on ethics have a very complex and articulated tradition that cannot be analysed in this context. To set up the thought of our educational project we chose the approach of Paul Ricoeur $(1990,1992)$, illustrious exponent of French phenomenology and hermeneutics. His position, in fact, offers a very interesting and original connection between the ethics and philosophy of care, even if he is a philosopher external to the debate about care.

His starting point is a clear distinction and definition of the two typical concepts of this conversational field: ethics and morality. After the identification of a common element, he establishes a precise difference.

What joins the two terms is their linguistic origin-both words have a similar meaning. "Ethos" in Greek and "mores" in Latin both indicate customs. Beyond this original commonality, Ricoeur allocates a different semantic space to the term "ethics" when compared to the word "morality": ethics refers to an understanding of "what is evaluated as good to do", while morality corresponds to "what is right to do". This distinction indicates that the central concern of ethics involves understanding what makes a good life. Meanwhile, morality means defining the rules and codes of behaviour. As a result, ethics falls firmly within the Aristotelian tradition, while morality remains in the Kantian domain.

Ricoeur's thinking seems to be particularly interesting because he assigns a primacy to ethics with respect to morality. Even though many rules can be formulated, the issues of life extend beyond any such boundaries. Clearly, it is beneficial to make use of Ricoeur's form of wisdom which considers every situation in its peculiarity. Ricoeur defines ethics as 
"aiming at a good life lived with and for others in just institutions" (1992, p. 172). However, as he himself notices (Ricoeur, 1990), the term "aiming" (souhait) feels too generic, and he suggests substituting it with the term "care"; as a consequence, he establishes ethics as a discourse about care for oneself, care for the others and care for the institutions (1990).

Since a relationship between care and ethics is established, it becomes difficult to ignore the moral feminine thought. The thinkers of ethics of care, in particular the ones starting from a feminist point of view such as Carol Gilligan (1987), Neil Noddings (1984, 2002), Eva Kittay (1999, 2002), and Virginia Held (2006), typically describe care as involving labor and relationships, as a relational practice that emphasizes mutual recognition and development, fostering wellbeing, social bonds, cooperation and human interdependence.

From this lens, we can talk about the situational value of the ethics of care as well as the general value of the ethics of justice. Following the reasoning formulated by Ricoeur, ethics is always situational, while morality produces rules. A phenomenological analysis of ethical reasoning highlights an important idea: even if ethical decision making is (and should be) situational, reasoning (even if it is attentive to the particular) never has to confront itself with a general dimension.

Therefore, we can make a distinction between the ethics of care and the ethics of justice. However, we must do so without attributing the regulatory character of morality to the ethics of justice. Similarly, on the other side, we must not confine the ethics of care to situational thinking: if we consider the reasoning at the foundation of caregivers' practical choices, we see dynamic thinking, analysing the particular, concrete situation while extensively considering the principles of judgement.

\section{Ethics and Virtue}

The ethics of justice has long been dominant, holding dominion over every cultural aspect. We find an example in Robert Coles (1986), a psychiatrist who defines morality as the capacity to distinguish what is right from what is wrong. Recently, the ethics of care has become more attractive. We consider them to be complementary, rather than opposing, forces. In fact, there exists a primacy of care in the light of which the ethics of justice starts making sense.

If we specifically analyse the ethics of care, we realize that its essence involves the search for the other's good. The most important theorists in the ethics of care (Mayeroff, 1990; Noddings, 1984; Held, 2006; Tronto, 1993) assume that the specificity of this ethical perspective consists of facilitating the other, giving shape to his humanity; this perspective implies that the caregiver feels responsibly invested in looking for the good in people, both others and himself. This vision is at the heart of ancient philosophy, in particular in the Socratic thought.

According to the Aristotelian perspective, virtue is a disposition that searches for the interpretation of the best-founded thing, to feel a certain sentiment when it is the time, orienting such feeling and using knowledge for a good target in the right way (Aristotle, Nicomachean ethics, book II, 6, 1106b). If thus intended, virtue becomes the condition of looking for a good quality of life (eudaimonia), the aim towards which ethics bends (Aristotle, Nicomachean ethics, book I, 1094a). The specificity of Aristotelian ethics, here taken as a reference, is its orientation to an ethics of virtue: it is founded on the assumption that the search for good relates to acting according to virtues (Aristotle, Nicomachean ethics, book I, 8, 1099a).

One can therefore assume the following: (a) care has an ontological primacy, (b) acting with care is moved by the intention to look for what is good, so we can talk about an ethics of care, and (c) ethics, in its living nucleus, is oriented to virtue: therefore, education to virtues finds a primary ontological foundation, which is an educative one.

What characterizes acting with care is being ready for the other, accepting the responsibility of putting the other at the centre of one's preoccupations when one perceives the other to be fragile and vulnerable. It is important to be sufficiently delocalized from oneself to concentrate on the other to the point of ascertaining his state of need and weakness, making it necessary to offer help. This willingness to responsibility, which in the politically most significant forms is applied to the "first come" principle (Lévinas, 2000), is translated into actions that can be indexed in the ethics of virtues field.

\section{But Can Virtues Be Taught?}

According to his own maieutic style, Socrates leaves open the question (Meno 70a). Aristotle instead gives a different answer to the question posed by Meno to Socrates: virtues can be taught. According to Aristotle, virtue is not an emotion or an ability, but it is a unique set of cognition, perception/recognition, emotion, desire, motivation, behaviour 
and conduct or style (Kristjánsson, 2007, 2015). Virtue is a habitual disposition to well acting. Peters stresses Aristotle's notion of moral education as habituation (Nicomachean Ethics) arguing that "the palace of reason is entered through the courtyard of habit" (Peters, 1963, pp. 54-55). But what Peters seems not to see is that "the account of moral motivation or habituation provided by Aristotle is tailored to a conception of moral wisdom or reflection as itself a matter of desiderative or affective engagement with more personal and interpersonal aspects of moral association" (Carr, 2007a, p. 392). Aristotle points out that "morality is grounded in practice - a point recognised in his famous analogy between the cultivation of virtues and the acquisition of skills" (Carr, 2007b, p. 373) and at the same time he clearly affirms that this character training is necessary but not sufficient to achieve virtue. Aristotle states that the full acquisition of the moral virtues of courage, temperance and justice "requires the principled reflection of practical wisdom" (p. 373), giving the chance to reconnect cognitive, social and motivational aspects of moral life which are often separated. So it is clear that the concept of virtue as a habit should not be misinterpreted as an irrational habit, but as a way of being that takes its form after the work of reason engaged in modelling its own being. In other words, virtue takes its form under the continuous and critically informed guide of reason (Pellegrino \& Thomasma, 1993, p. 5). The debate on Aristotle's virtue ethics is intense and articulated. What is fundamental for our research is the idea that virtues can be learned through education and practice.

\section{Perspectives on Ethical Education}

A new attention to ethical education has emerged since several years. The international literature generally discusses "moral education". Our position prefers to talk about "ethical education" because ethics deals with the project of a good life, while the word moral, in our culture, is fraught with meanings that sometimes are very heavy, resounding of moralism. However, because so many international scholars use the term "moral education", it is necessary to examine this pedagogical perspective using its own peculiar language (Tronto, 1993).

\section{The "Moral Education" Position}

A leading figure of the "moral education" position is William Damon. Damon, not free from moralistic tones, observes that when the moral education position is examined, it is necessary to deal with the theme of values in terms of the following question: which values should be taught to young people? (Damon, 1998). However, it is difficult to find a shared position to answer this question. In fact, there is no general agreement about values or ethical rules. Meanwhile, the educational world has to deal with the lack of wisdom that would be necessary to understand how to practice ethical education because we have not yet committed sufficient thought to this specific philosophy of education. Beyond philosophical research, we can find two different pedagogical cultures dealing with "moral education": "character education" and "moral reasoning". Each quoted opinion is, of course, only a definition that summarizes and identifies a very complex field in which various authors present different programs and emphasis, most of them built in strict dialogue with other theories. It is not the purpose of this article to propose a complete literature review in every field of ethics education. We just try to focus on the main common characteristics of each position, choosing some authors that could present some peculiarity and contribute to found a solid pedagogical background to our educative program.

\section{The "Character Education" Position}

A very related theory in ethics education is character education.

Character education is a complex concept to be defined and also an articulated theory: it is founded in different disciplines and requires a multifaceted educational strategy even because the concept of character is complicated and has to integrate the different aspects of the person (e.g. conscience, empathy, moral reasoning, values, moral identity, etc.). Berkowitz (2011) defines character education as the intentional development, in educational contexts, of youth's citizenship agency, characterized by responsibility, pro-social behaviors and respect.

Howard et al. (2004) affirm that there are three main approaches to character education: "the cognitive-developmental approach (often called moral education) which gives primacy to 'knowing the good', the caring approach which emphasizes 'desiring the good', and the traditional character education, which sees 'doing the good' as fundamental" (p. 190). These approaches are frequently mixed in the classroom practice and applied with other educational programs: service learning programs engaging students in active experiences to promote values (Stott \&. Jackson, 2005); conflict resolution programs (Howard, Berkowitz, \& Schaeffer, 2004); the Child Development Project, a comprehensive longitudinal intervention project designed to enhance the social and moral development of children through systematic changes in the classroom, school, and home environments (Watson et al., 1989; Battistich et al., 1991; Solomon et al., 1992); cognitive development programs that involve classroom discussions of moral dilemmas, through story telling (or history) used to communicate virtues (Lickona, 1978; 1993; 1997). 
Even if the positions are different, according to Lickona (1997, p. 95) "character education is the deliberate effort to teach virtue": it is an effort to educate good character based on core virtues that are good both for the individual and the society.

This identification between character education and virtue ethics can be explained with the fact that a virtue-centred vision assumes the "character" of the person who acts to be the key factor (Schneewind, 1990). The character education position claims inspiration from the Aristotelian tradition (Sichel, 1988). Noddings (2002) describes the peculiarity of the character education position, which contrasts with "moral reasoning": she affirms that if the moral reasoning perspective gives importance to reasoning in the moral field (problem solving and development of critical thinking), character education deals with virtue education. In such a definition, character education becomes simple socialization, uninterested in the development of thinking. In fact, Noddings (2002) considers character education to be a path of development able to introduce the person into a community characterized by strong moral cohesion. Even many authors in the tradition of character education talk about processes of "moral reasoning or cognitive development" (Howard et al., 2004; Berkowitz, 2011), including discussion based components (as opposed to social indoctrination), this approach to ethical education tends not to underline the development of autonomous and critical thinking necessary to deal with other people; its fundamental purpose seems to groom young people to enter into a tradition, a process that occurs through story telling (McIntyre, 1981).

\section{Moral Reasoning}

The moral reasoning position also uses stories as instruments to develop critical thinking. However, there is an important difference: moral reasoning does not consist of the prevalent habits of a certain society, but of the Enlightenment ideals. The pedagogy of moral reasoning takes as its reference the theories of Kohlberg (1981, 1984) and his associates (Colby \& Kohlberg, 1987; Power, Higgins, \& Kohlberg, 1989). These theorists provide radical critiques of character education theory, because they think it drifts to a form of indoctrination. They question the possibility of directly teaching virtues, noting that such an approach requires a form of modelling that diverges entirely from the authentic meaning of education. Therefore, liberal American culture positively views theories of educational ethics promoting moral reasoning; meanwhile, conservative educators tend to follow the character education position inspired by illuminist philosophy.

The psychological moral development theory elaborated by Kohlberg $(1981,1984)$ has played an important role in the psychological and pedagogical fields. Through his research, Kohlberg intended to explain the development of moral thinking. He asserted that moral development evolves through two stages at three different levels: two at a preconventional level, two at a conventional level, and two at a post-conventional level. The first stage is defined as heteronomous morality; the second as individualistic morality; the third as normative interpersonal morality; the forth as social system morality; the fifth as human rights morality; the sixth as universal ethical principle morality. These processes involve the use of what Colby and Kohlberg (1987) called a "moral point of view", defined as "a point of view that ideally all human beings should take toward one another as free and equal autonomous persons. This means equal consideration of the claims or points of view of each person affected by the moral decision to be made" (p. 30). The above-mentioned stages develop in an unvaried sequence. We can summarize the principles of Kohlberg's theory in three assumptions: (a) the criterion for moral development is maturity of moral judgment (Colby \& Kohlberg, 1987, pp. 1-2), (b) moral judgment is organized in "structures of the whole" (p. 8), and (c) the new structures of moral reasoning that people acquire as they develop "transform and displace" the previous ones (p. 7).

This stage vision of moral development allowed Kohlberg to theorize that only a limited percentage of people reaches the highest stages; we thus can assume that there is a so-called moral élite (Tronto, 1993). Another problematic aspect of his theory is that it does not pretend to be a descriptive theory of moral development-it also prescribes the "right" direction of this development (Tronto, 1993).

The most cutting and culturally influential critique to that theory of moral development came from Carol Gilligan who stated that the people involved in Kohlberg's studies were all male. Starting from this observation, she hypothesizes that his theory was corrupted by sexism. Conducting research according to Kohlberg's model but with a different research design, Gilligan theorized the existence of a different moral voice in addition to justice: the voice of care. She distinguished a practice of justice, concerned with the application of rights and rules, from a morality of care, concerned with the preservation and nurturing of human relationships (Gilligan, 1982). While care assumes responsibility and relationship as central concepts, justice focuses on rights and rules. As such, the ethics of care concentrates on concrete living circumstances, while the ethics of justice concerns itself with a more formal and theoretical plan. Ultimately, care fundamentally consists of a way of acting, while justice means defining principles (Tronto, 1993).

Another radical critique to Kohlberg's, and also to Piaget's, theory is the Domain Theory by Turiel and collegues (Turiel, 1998, 2002, 2010; Smetana, 1995, 2006; Nucci, 1981; Nucci \& Nucci, 1982; Nucci \& Narvaez, 2008; Killen \& Smetana, 
2008, 2010). Like Kohlberg, they assume a constructivist vision about children's understanding of the world, recognize the role of cognitive development to moral understanding, and stress the role of peers interactions to moral growth. In opposition to his theory, instead, they affirm that the distinction between moral and non-moral concepts does not occur out of a global fusion of social concepts (as Kohlberg stated), through a process of differentiation and hierarchical integration. According to the Domain Theory, instead, moral, conventional, and personal domains are separated and self-regulating developmental systems: they are neither developmentally ordered, nor hierarchically oriented and coexist from early age, even if they change qualitatively with age.

There are also critiques of the moral reasoning approach itself as accurately represented by moral psychology: for example, the contribution of Haidt and Greene and their Social Intuitionist approach (Greene et al., 2001; Haidt, 2001; 2007; Haidt \& Graham, 2007) paid attention to the role of emotion and intuition in moral judgment and action, and was very influential in challenging the moral reasoning in educational approach that tended to forget the complexity of the "mind".

\section{Education to the Ethics of Virtues: The Philosophy of the "MelArete" Project}

Taking the theory of care and Aristotle's virtue ethics as a foundation, we propose a different interpretation of ethical education, education to the ethics of virtue according to the ethics of care. In Greek, one of the terms describing care is melete, and the term for virtue is arete. From these terms, we derived the name of our ethical educational project, MelArete (Mortari \& Mazzoni, 2014).

This project is based on the following pedagogical question: How can we orient the person to pay attention to virtues and to reflect about the values they can assume in order to realize a good quality of life?

Education, to be considered valid, cannot demand the teaching and realization of the good according to a geometrical and unquestionable vision. At the same time, a philosophy of education must dare to follow possible educative paths based on horizons of meaning. Since the ethics field is not dogmatic, any philosophy of education must seek to maintain an open and critical perspective. Meanwhile, a coherent educational method is needed to nurture young minds and build the awareness necessary for a critical, autonomous, and reflective disposition.

What is the relationship between MelArete, the character education position, and moral reasoning?

Similar to the character education position, MelArete considers virtue to be a key concept for ethical education; however, we do not confuse ethics with mere socialization. Aligned with moral reasoning, MelArete gives importance to the development of reasoning, cultivating analytical, critical, and deliberative thinking while avoiding abstraction and conceptualism.

MelArete is an expression of "care theory"; in this project, the acquisition of virtues does not follow a top-down, dogmatic model, but passes through a radical critical analysis of every aspect of experience.

Ultimately, we can say that MelArete assumes two aims: cultivating passion for the research of the good while developing the capability to consider ethical questions analytically and critically.

In our educational project with children, we obtain these aims through the following methods:

- $\quad$ Conversations: we use conversations to promote intersubjective thought, where people can talk with others, as in "Socratic Circles" (Copeland, 2005).

- $\quad$ Narratives: we seek a "narrative shift" (Ricoeur, 1984-88; Bruner, 1990). By reading and writing stories about virtues involving people within ethical dilemmas, learners become more able to face them.

- $\quad$ Vignettes and games: through a playful language, we present children ethical dilemmas or critical situations, and we stimulate their creative thought in the ethical field.

- The "Diary of virtues": we invite children to write a diary in order to cultivate virtues in everyday life and reflect on their actions .

The MelArete project has been proposed to children during the school year 2016-2017 and the data collected are in the phase of analysis. Starting from the philosophy referred in this essay we elaborated two different curricula (even if 
similar) in order to interact with different aged children: one curriculum was thought for primary school, the second for kindergarten. In our research we experimented the project with:

- 6 primary school $4^{\text {th }}$-grade classes, involving 106 nine y.o. children;

- 8 kindergarten classes, involving 57 five y.o. children.

The seven schools chosen for the research were set in different Italian cities located in the North and in the Centersouthern regions, and are characterized by different social-economical backgrounds.

The teachers involved were 24 (11 in primary schools and 13 in kindergartens).

After a long phase of preparation of the tools and coordination with the schools, the project started with its practical phase in October 2016 and finished in June 2017. The researchers met the classrooms twice a month: the fifteen days between one meeting and the another gave children a sufficient time to reflect and a tranquil time to learn. The project consisted in 12 meetings with every class.

The data collected are: conversations between children and the researcher focused on virtues, presented through narratives and ludic activities; texts written by children (tales, personal reflections and the "diary of virtue") and drawings supported by children's description recorded by the researcher and the teachers (in particular in kindergarten).

Even if a deep and organic analysis of data has just started, the framework of the research is clear and defined. Therefore, some findings or preliminary considerations can be presented.

The purpose of the research is to understand what kind of ethical thought is the project able to foster in children.

Data will be analysed following a phenomenological approach (Mortari, 2007; Tarozzi \& Mortari, 2010) in order to show the "essence" of children's ethical thought.

From a preliminary analysis, and after deep debate with the teachers involved, we can state that the project helped children to understand the concept of virtue (in most of cases previously totally ignored) and consider it as a granted framework in order to reflect on actions while looking for the good. Children have been able to recognize the different components of a virtuous action (thought, emotion, consequences, choice), acted or seen; and they could recognize the ethical "call" inside dilemmas of everyday life.

The capacity of analysis and reflection resulted to be so increased that children have been able not only to name a specific virtue and choose a coherent action in critical situation, but also to understand the complexity of every situation and action, so that they could identify different "nuances" or different virtues in a single action.

\section{References}

Arendt, H. (1958). The Human Condition. Chicago: University of Chicago Press.

Aristotle (2011). Nicomachean Ethics. Trans. R.C. Bartlett, \& Collins, S. D. Chicago: University of Chicago Press.

Battistich, V. , Watson, M., Solomon, D., Schaps, E., \& Solomon, J. (1991). The Child Development Project: A comprehensive program for the development of prosocial character. In W. M. Kurtines \& J. L. Gewirtz (Eds.), Handbook of moral behavior and development: Vol 3. Application (pp. 1-34). New York: Lawrence Erlbaum.

Berkowitz, M. W. (2011). Understanding effective character education. The Center for Spiritual and Ethical Education. CSEE Connections. Retrieved http://www.character.org/wp-ontent/uploads/2011/12/UnderstandingEffectiveCharacter-Education.pdf (ver. 25.06.2017).

Bruner, J.S. (1990). Acts of meanings. Cambridge: Harvard University Press.

Carr, D. (2007a). Moralized psychology or psychologized morality? Ethics and psychology in recent theorizing about moral and character education. Educational theory, 57(4), pp 389-402.

Carr, D.(2007b). Character in Teaching. British Journal of Educational Studies, 55(4), 369-389. 
Colby, A., \& Kohlberg, L. (1987). The measurement of moral judgment. Vol 1: Theoretical foundations and research validation. New York: Cambridge University Press.

Coles, R. (1986). The moral life of children. New York: Atlantic Monthly Press.

Copeland, M. (2005). Socratic Circles. Portland, Maine: Stenhouse Publishers.

Damon, W. (1988). The moral child. New York: The Free Press.

Gilligan, C. (1982). In A Different Voice, Cambridge, Massachusetts: Harvard University Press.

Greene, J.D., Sommerville, R.B., Nystrom, L.E., Darley, J.M., \& Cohen, J.D. (2001). An fMRI study of emotional engagement in moral judgment. Science, 293, 2105-2108.

Haidt, J. (2001). The emotional dog and its rational tail: A social intuitionist approach to moral judgment. Psychological Review, 108, 814-834.

Haidt, J. (2007). The new synthesis in moral psychology. Science, 316, 998-1002.

Haidt, J., \& Graham, J. (2007). When morality opposes justice: Conservatives have moral intuitions that liberals may not recognize. Social Justice Research, 20, 98-116.

Heidegger, M. (1996). Being and time. Trans. J. Stambaug. Albany, NY: State of New York University Press. (Original work published 1927).

Held, V. (2006). The Ethics of Care. New York: Oxford University Press.

Howard, R. W., Berkowitz, M. W., \& Schaeffer, E. (2004). Politics of character education. Educational Policy, 18(1), 188215.

Killen, M., \& Smetana, J. (2008). Moral judgment and moral neuroscience: Intersections, definitions, and issues. Child Developmental Perspectives, 2, 1-6.

Killen, M., \& Smetana, J. (2010). Future directions: social development in the context of social justice. Social Development, 19, 642-657.

Kittay, E. (1999). Love's labor. Essays on Women, Equality, and Dependency. New York and London: Routledge.

Kittay, E. (2002). When Caring is Just and Justice is Caring: Justice and Mental Retardation (pp. 257-276). In E.F. Kittay \& E.K. Feder (Eds.). The Subject of Care. Boston: Rowman \& Littlefield Publishers.

Kohlberg, L. (1981). Essays on moral development, Vol. I: The philosophy of moral development. San Francisco: Harper \& Row.

Kohlberg, L. (1984) Essays in moral development, Vol. II: The psychology of moral development. San Francisco: Harper and Row.

Kristjánsson, K. (2007). Aristotle, Emotions, and Education. Aldershot: Ashgate.

Kristjánsson, K. (2015). Aristotelian character education. London; New York: Routledge.

Lévinas, E. (2000). Entre nous. Essays on Thinking-of-the-Other. Trans. M.B. Smith, \& B. Harshav. New York: Columbia University Press (Original work published 1991).

Lickona, T. (1978). Helping teachers become moral educators. Theory into Practice, 17(3), 258-266.

Lickona, T. (1993). The return of character education. Educational Leadership, 51(3), 6-11.

Lickona, T. (1997). The teacher's role in character education. The Journal of Education, 179(2), pp. 63-80. 
Mayeroff, M. (1990). On Caring, New York: Harper Collina Publishers.

McIntyre, A. (1981). After virtue. Notre Dame, IN: University of Notre Dame Press.

Mortari, L. (2006). La pratica dell'aver cura. Milano: Bruno Mondadori.

Mortari, L. (2007). Cultura della ricerca e pedagogia. Roma: Carocci.

Mortari, L. (2013). Aver cura della vita della mente. Roma: Carocci.

Mortari, L. (2015). Filosofia della cura. Milano: Raffaello Cortina.

Mortari, L., \& Mazzoni V. (2014). Le virtù a scuola. Questioni e pratiche di educazione etica. Verona: Cortina.

Mortari, L., \& Saiani, L. (Eds.) (2014). Gestures and thoughts of caring. New York-Boston: McGraw-Hill Education.

Nancy, J.L. (2000). Being Singular Plural. Trans. R. Richardson \& A. O’Byrne. Stanford (CA): Stanford University Press (Original work published 1990).

Noddings, N. (1984). Caring. Berkeley: University of California Press.

Noddings, N. (2002). Starting at home. Caring and Social Policy. Berkeley- Los Angeles: University of California Press.

Nucci, L. (1981). The development of personal concepts: a domain distinct from moral and social concepts. Child Development, 52, 114-121.

Nucci, L., \& Narvaez, D. (Eds.) (2008), Handbook of moral development and character education. Oxford, UK: Routledge.

Nucci, L., \& Nucci, M. (1982). Children's social interactions in the context of moral and conventional transgressions. Child Development, 53, 403-412.

Pellegrino, E.D., \& Thomasma, D.C. (1993). The virtues in medical practice. New York: Oxford University Press.

Peters, R.S. (1963). Reason and Habit: The Paradox of Moral Education. in W.R. Niblett (Ed), Moral Education in a Changing Society. London: Faber and Faber.

Plato (1871). The dialogue of Plato. Trans. B. Jowett. Oxford: Clarendon press.

Power, F. C., Higgins, A., \& Kohlberg, L. (1989). Lawrence Kohlberg's Approach to Moral Education. New York: Columbia University Press.

Pulcini, E. (2009). La cura del mondo. Torino: Bollati Boringhieri.

Ricoeur (1984, 1986, 1988). Time and Narrative. 3 vols. Trans. K. Blamey, \& D. Pellauer. Chicago: University of Chicago Press (Original work published 1983, 1984, 1985).

Ricoeur, P. (1990). Ethique et morale. Revue de l'Institut catholique de Paris, 34, avril-juin, 131-142.

Ricoeur, P. (1992). Oneself as Another. Trans. Blamey, K.; Chicago: University of Chicago Press, (Original work published 1990).

Schneewind, J.B. (1990) The misfortunes of virtues. Ethics, 1, 42-63.

Sichel, B. (1988). Moral Education: Character, Community, and Ideals. Philadelphia: Temple University Press.

Smetana, J. (1995). Morality in context: abstractions, ambiguities, and applications. In R. Vasta (Ed.), Annals of child development (Vol. 10; pp. 83-139). London: Jessica Kingsley.

Smetana, J. (2006). Social-cognitive domain theory: consistencies and variations in children's moral and social judgments. In M. Killen, \& J. Smetana (Eds.), Handbook of moral development (pp. 119-153). Mahwah, NJ: Erbaum. 
Solomon, D. , Watson, M., Battistich, V., Schaps, E., \& Delucchi, K. (1992). Creating a caring community: Educational practices that promote children's prosocial development. In F K. Oser, A. Disk, \& J.-L. Patry (Eds.), Effective and responsible teaching: The new synthesis. San Francisco: Jossey-Bass.

Stott, K., \& Jackson, A. (2005). Using service learning to achieve middle school comprehensive guidance goals. Professional School Counseling, 9(2), 156-159.

Tarozzi, M., \& Mortari, L. (2010). Phenomenology and human science research today. Bucharest: Zeta Books.

Tronto, J. (1993). Moral boundaries: a political argument for an ethic of care. New York: Routledge.

Turiel, E. (1998). The development of morality. In W. Damon (Series Ed.) \& N. Eisenberg (Vol. Ed.), Handbook of child psychology. Vol. 3: Social, emotional, and personality development (pp. 863-932). New York: John Wiley.

Turiel, E. (2002). The culture of morality: Social development, context, and conflict. Cambridge: Cambridge University Press.

Turiel, E. (2010). Domain specificity in social interactions, social thought, and social development. Child Development, $81,720-726$.

Watson, M. , Solomon, D., Battistich, V., Schaps, E., \& Solomon, J. (1989). The Child Development Project: Combining traditional and developmental approaches to values education. In L. Nucci (Ed.), Moral development and character education: A dialogue (pp. 51-92). Berkeley, CA: McCutchan. 